\title{
STUDIES ON THE EFFECT OF DOPING AGENT ON THE STRUCTURE OF POLYANILINE
}

\author{
Chemistry Department, AI-Azhar University-GAZA, \\ P.O.Box 1277, GAZA, Palestine; omarmelad@yahoo.com
}

Received: M ay 22, 2015 / Revised: J une 08, 2015 / Accepted: September 22, 2015

(C) Melad O., Jarur M., 2016

\begin{abstract}
Polyaniline (PANI) doped with hydrochloric acid $(\mathrm{HCl})$, sulpharic acid $\left(\mathrm{H}_{2} \mathrm{SO}_{4}\right)$ and formic acid $(\mathrm{HCOOH})$ was synthesized by a chemical oxidative polymerization technique. The oxidizing agent used for this method is potassium dichromate. The polymer products were characterized by FTIR and UV-visible spectroscopy. The FTIR results showed that the doping degree of PANI-HCOOH is the greatest one. A successful doping of $\mathrm{HCOOH}$ in PANI was observed in UV-visible spectroscopy. Three steps decomposition observed from the thermo gravimetric analysis (TGA).
\end{abstract}

Keywords: polyaniline, $\mathrm{H}_{2} \mathrm{SO}_{4}$, conductivity, thermal analysis, FTIR, dopant.

\section{Introduction}

Conducting polymers have been extensively studied in the last years, confirmed by 2000 Nobel prize in chemistry for the discovery and development of conductive polymers (Heeger, 2001) [1]. Among these polymers polyaniline (PANI) has been of particular interest because of its cheap monomer, simple synthesis technology [2, 3], high conductivity upon doping with acids, high chemical and electrical stability, and good environmental stability [4-12]. The novel properties of PANI have shown its potential in technological applications such as rechargeable batteries, electro chromic displays, high performance composites and sensors [13, 14]. PANI has three different forms, Leucomeraldine (fully reduced form), emeraldine base (50\% oxidized form) and pernigraniline (100\% oxidized form) [15]. Among different oxidation states of PANI, the emeraldine salt (ES) is the only conducting form of PANI, which has been extensively studied during last years. Nonetheless, the emeraldine base (EB), which is another form of PANI, can be converted to emeraldine salt (ES), and vice versa, by protonation/deprotonation with acid/base, as depicted in Fig. $1[16,17]$.

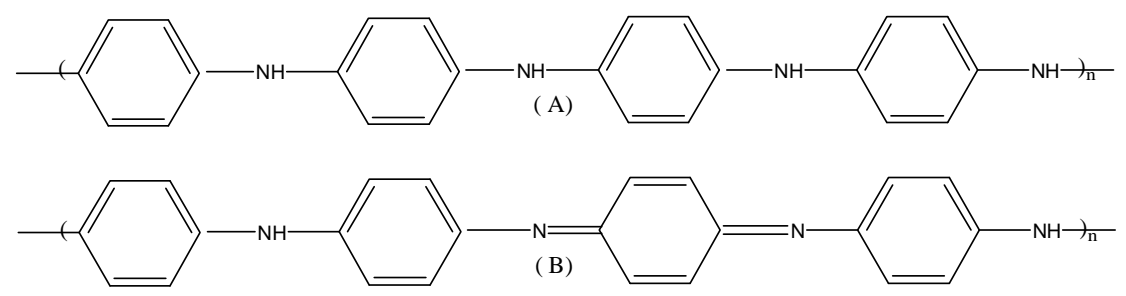

Fig. 1. Four different redox forms of polyaniline: leucoemeraldine base (fully reduced form) (A); emeraldine base (half-oxidized form) (B); conducting emeraldine salt (half-oxidized and protonated form) (C) and pernigraniline base (fully oxidized form) (D)
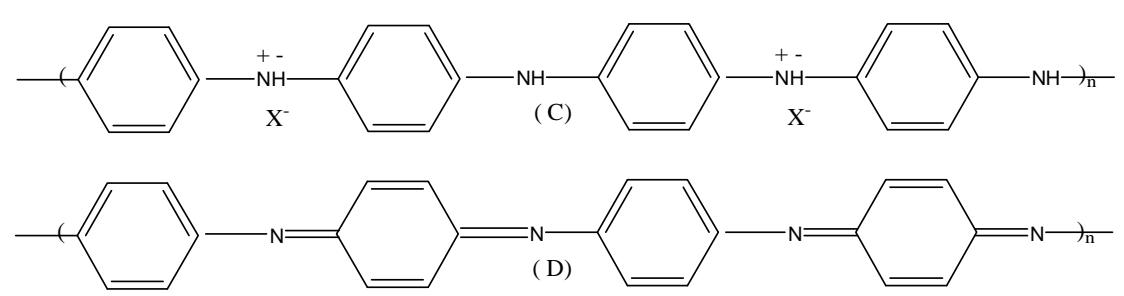
Polyaniline can be chemically synthesized in acidic media using an oxidizing agent such as potassium dichromate, ammonium persulphate, hydrogen peroxide, cerium nitrate, etc. [18]. The properties of the conductive PANI are affected by the type of dopant ion employed. The dopants increase the solubility as well as the conductivity of polyaniline [19-22]. Recently, some researchers have proposed the effect of dopant on the structure of PANI $[23,24]$ or PANI derivatives $[25,26]$. Polyaniline doped or protonated with acids like $\mathrm{HCl}$, $\mathrm{H}_{2} \mathrm{SO}_{4}$ or some organic sulphonic acid exhibited good electrical conductivity value. Also, the dopants having carboxyl group were reported to increase the solubility of polyaniline [27].

In this work we have prepared PANI by the chemical oxidation method at room temperature and studied the effect of different dopants: hydrochloric acid $(\mathrm{HCl})$, sulpharic acid $\left(\mathrm{H}_{2} \mathrm{SO}_{4}\right)$ and formic acid $(\mathrm{HCOOH})$ on the structure of the polymer which was prepared using FTIR, UV-visible, thermo gravimetric analysis (TGA) and conductivity measurements.

\section{Experimental}

\subsection{M aterials}

Materials used are aniline (ANI) (ADWIC, Egypt), Potassium dichromate (Merck, Germany). The acids used are hydrochloric acid $(\mathrm{HCl} 32 \%)$, sulpharic acid $\left(\mathrm{H}_{2} \mathrm{SO}_{4}\right.$ $98 \%$ ) and formic acid ( $\mathrm{HCOOH} 98 \%)$. Acetone and dimethylsulfoxide (DMSO) are used for filtration and UV-visible measurements respectively. All chemicals, acids and solvents were used as received without further purification.

\subsection{M easurements}

FTIR spectra were recorded using FTIR 8201PC (SHIMADZU) instrument by KBr Pellets techniques. For measuring the UV-visible absorption spectra, spectrophotometer (UV-1601 SHIMADZU) was used. The thermal studies were performed using Mettler-Toledo 851 thermo gravimetric analysis (TGA) in a nitrogen atmosphere from room temperature to $873 \mathrm{~K}$ at heating rate of $10 \mathrm{~K} / \mathrm{min}$. A crucible of platinum containg $15 \mathrm{mg}$ of sample was used in the TGA analysis. Conductivity measurements were made at room temperature using conductivity meter (CM-30V).

\subsection{Synthesis of PANI with Different Dopants ( $\mathrm{HCl}, \mathrm{H}_{2} \mathrm{SO}_{4}$ and $\mathrm{HCOOH}$ )}

Aniline $(5 \mathrm{~g}, 0.054 \mathrm{~mol})$ was dissolved in $75 \mathrm{ml}$ of $1.0 \mathrm{M} \mathrm{HCl}$ and kept at $298 \mathrm{~K}$. Potassium dichromate $12.3 \mathrm{~g}$ was dissolved in $70 \mathrm{ml} 1.0 \mathrm{M} \mathrm{HCl}$ and also kept at $298 \mathrm{~K}$. The two solutions were mixed, filtered using a Buchner funnel and flask, washed with acetone and then dried in an oven at $873 \mathrm{~K}$ for $48 \mathrm{~h}$. The above procedure repeated using $1.0 \mathrm{M} \mathrm{H}_{2} \mathrm{SO}_{4}$ and $1.0 \mathrm{M} \mathrm{HCOOH}$ respectively.

\section{Results and Discussion}

\subsection{Fourier Transform Infrared (FT-IR)}

FTIR is one of the most important methods of spectroscopy; in our work the importance of FTIR is concentrated in the comparison of band position for determing functional groups present in both pure and doped polyaniline. The characteristic of FTIR can be distinguished between two important rings: benzenoid (B) and quinoid $(\mathrm{Q})$ in $1400-1600 \mathrm{~cm}^{-1}$ region in the spectrum in both cases of pure and doped polymers [28, 29]. Fig. 2 shows the FTIR spectra of PANI-HCl, PANI- $\mathrm{H}_{2} \mathrm{SO}_{4}$ and PANI-HCOOH respectively. The bands with maximum at 1585 and $1508 \mathrm{~cm}^{-1}$ in the spectra of PANI-HCl are assigned to quinoid and benzenoid ring respectively, 1581 and $1507 \mathrm{~cm}^{-1}$ band, 1590 and $1511 \mathrm{~cm}^{-1}$ band also appeared in the spectrum of PANI- $\mathrm{H}_{2} \mathrm{SO}_{4}$ and PANI$\mathrm{HCOOH}$ respectively, the ratio of IQ/IB can be used to estimate the degree of oxidation on polyaniline [30]. We observed similarity in the ratio IQ/IB for three dopants used indicating the similarity of the oxidation degree in different dopants used. The intensity of peaks depends on factors such as polymer coil size, the nature of polymersolvent polymer doping. The spectrum of PANI- $\mathrm{H}_{2} \mathrm{SO}_{4}$ (Fig. 2b) has a small intensity band at $1397 \mathrm{~cm}^{-1}$, which is attributed to stretching of $\mathrm{C}-\mathrm{N}$ bonds. The band at $1314 \mathrm{~cm}^{-1}$ in the spectrum of PANI-HCl (Fig. 2a) may be attributed to the stretching of $\mathrm{C}-\mathrm{N}$ bonds of secondary aromatic amines and displacement of $\pi$-electrons, induced by the acid doping of the polymer, while absorption bands are at 1312 and $1311 \mathrm{~cm}^{-1}$ for PANI- $\mathrm{H}_{2} \mathrm{SO}_{4}$ and PANI$\mathrm{HCOOH}$ respectively. This shift to lower wave number may be attributed that the doping degree of PANI$\mathrm{HCOOH}$ is the greatest one, which prefers the movement of $\pi$-electrons and make the displacement to a lower wave number. The band at $1140 \mathrm{~cm}^{-1}$ is the most intense in the PANI- $\mathrm{H}_{2} \mathrm{SO}_{4}$ (Fig. 2b), may attributed to vibration of $-\mathrm{NH}^{+}=$structure formed in the acid doping process of PANI, this band is shifted to $1151 \mathrm{~cm}^{-1}$ in the PANI$\mathrm{HCOOH}$ (Fig. 2c) indicating that the doping level of PANI$\mathrm{HCOOH}$ is higher than that of PANI-HCl and PANI- $\mathrm{H}_{2} \mathrm{SO}_{4}$ respectively. Also the band at $1397 \mathrm{~cm}^{-1}$ in the PANI- $\mathrm{H}_{2} \mathrm{SO}_{4}$ (Fig. 2b) can be attributed to a case of sulphate group to the aromatic ring of PANI. The region between $700-900 \mathrm{~cm}^{-1}$ corresponds to the aromatic ring deformation and $\mathrm{C}-\mathrm{H}$ bond vibrations out of ring plane [31]. 


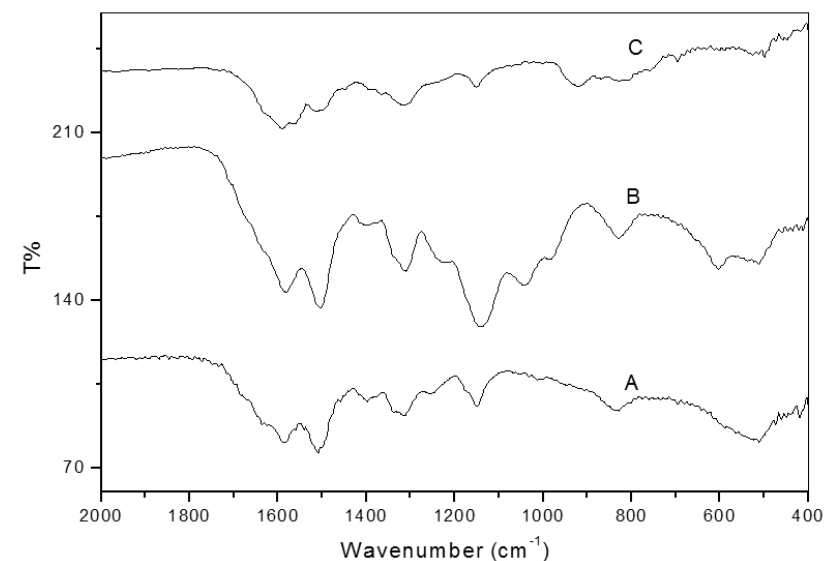

Fig. 2. FTIR spectra of PANI doped with $\mathrm{HCl}(\mathrm{A}), \mathrm{H}_{2} \mathrm{SO}_{4}$ (B) and $\mathrm{HCOOH}(\mathrm{C})$

\subsection{UV-Visible}

The UV-vis spectra of the soluble parts in DMSO of PANI synthesized with the use of $\mathrm{K}_{2} \mathrm{Cr}_{2} \mathrm{O}_{7}$ as an oxidant in different dopants $\left(\mathrm{HCl}, \mathrm{H}_{2} \mathrm{SO}_{4}\right.$ and $\left.\mathrm{HCOOH}\right)$ respectively are shown in Fig. 3 . The band observed at $364 \mathrm{~nm}$ for PANI-HCl corresponds to $\pi-\pi^{*}$ transition of aniline and/or aniline radicals. The benzenoid ring $\left(\pi-\pi^{*}\right)$ is related to the conjugation between adjacent phenyl rings in a polymer chain. A shift from the band at 364 to $294 \mathrm{~nm}$ observed in Fig. 3c, may be attributed to the steric effect of $-\mathrm{COOH}$ group of the formic acid which causes the lower degree of conjugation as well as the hindering charge transfer between chains; this indicates a successful doping of $\mathrm{HCOOH}$ in the polyaniline. The broad bands at $578-625 \mathrm{~nm}$ is due to $\pi-\pi^{*}$ transitions of the quinoid ring.

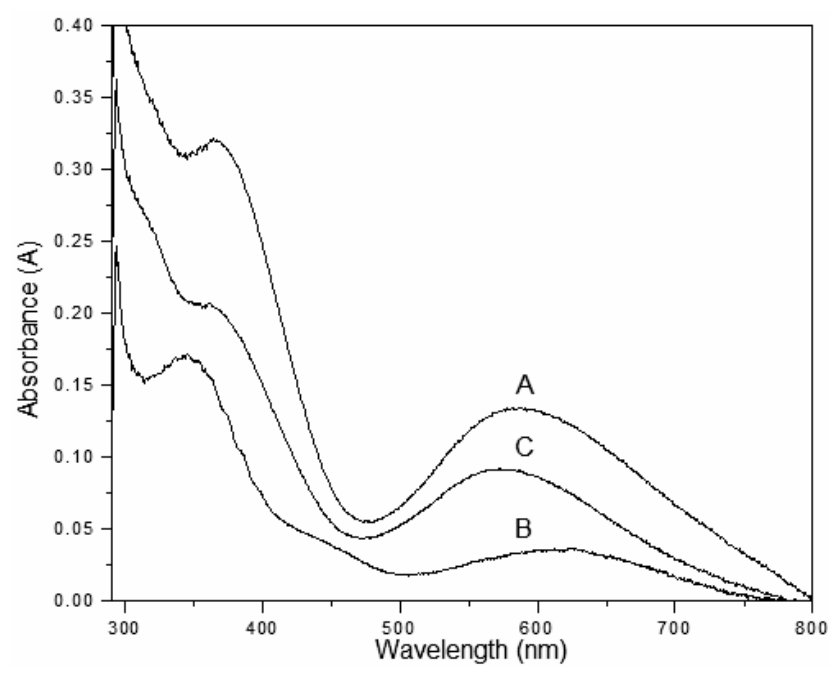

Fig. 3. UV-vis spectra of PANI doped with $\mathrm{HCl}(\mathrm{A}), \mathrm{H}_{2} \mathrm{SO}_{4}$ (B) and $\mathrm{HCOOH}(\mathrm{C})$

\subsection{Electrical Conductivity}

The electrical conductivity values of the polyaniline (PANI-HCl, PANI- $\mathrm{H}_{2} \mathrm{SO}_{4}$ ) and PANI$\mathrm{HCOOH}$ ) are presented in Table1.

Table 1

\section{Electrical conductivity of PANI with different dopants}

\begin{tabular}{|c|c|}
\hline Polyaniline (PANI) & Conductivity, $\mathrm{S} \cdot \mathrm{cm}^{-1}$ \\
\hline PANI-HCl & 3.087 \\
\hline PANI- $\mathrm{H}_{2} \mathrm{SO}_{4}$ & 0.121 \\
\hline PANI-HCOOH & 3.217 \\
\hline
\end{tabular}
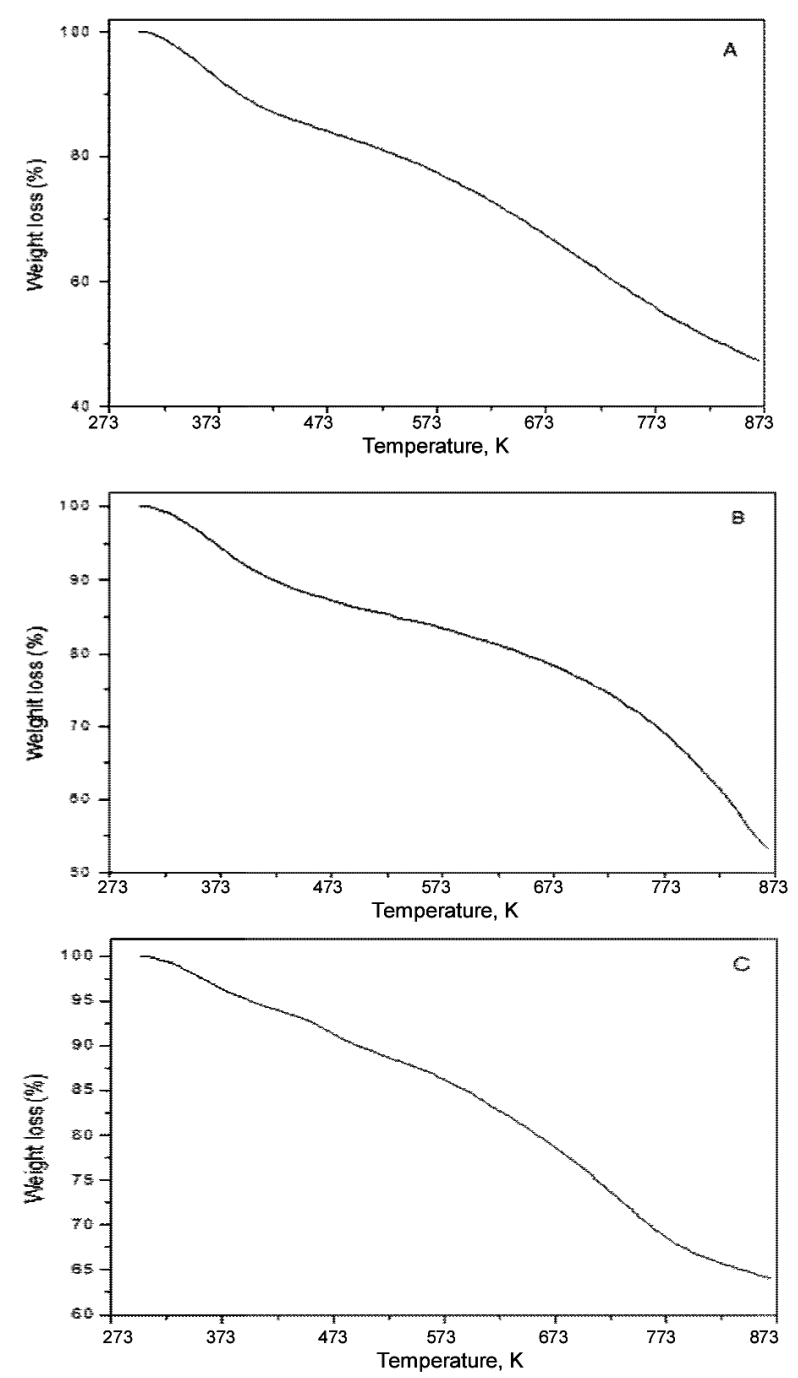

Fig. 4. Athermograms of PANI doped with with $\mathrm{HCl}(\mathrm{A})$, $\mathrm{H}_{2} \mathrm{SO}_{4}(\mathrm{~B})$ and $\mathrm{HCOOH}(\mathrm{C})$

From Table 1, the conductivity were found to be in the order $\mathrm{PANI}-\mathrm{HCOOH}>\mathrm{PANI}-\mathrm{HCl}>\mathrm{PANI}-\mathrm{H}_{2} \mathrm{SO}_{4}$. 
The lower value of the conductivity in the case of PANI$\mathrm{H}_{2} \mathrm{SO}_{4}$ is attributed to the decrease of efficiency of the charge transfer between the polymer chains when $\mathrm{H}_{2} \mathrm{SO}_{4}$ is used as a dopant for PANI. However the electrical conductivity values of PANI-HCOOH are the highest indicating that the doping degree of PANI doped with formic acid is the best.

\subsection{Thermogravimetric Analysis (TGA)}

Fig. 4 shows the thermogravimetric analysis (TGA) for samples of doped polyanilines (PANI-HCl, PANI$\mathrm{H}_{2} \mathrm{SO}_{4}$ and PANI-HCOOH). Three steps can be seen in the decomposition curve related to the loss of water molecules present in the polymer PANI, loss of dopant, and complete degradation and decomposition of the polymer bachbone. Within the range of $373-423 \mathrm{~K}$ it is the loss of water molecules in the polymer PANI with different dopants. The second step loss at $433-523 \mathrm{~K}$ is the loss of dopant which increases in PANI-HCOOH and decreases in PANI- $\mathrm{H}_{2} \mathrm{SO}_{4}$. This is in an agreement with our conductivity measurements in which the conductivity of PANI-HCOOH is high, showing the efficient doping of the polymer chains. We conclude that PANI-HCOOH loses a greater weight than PANI-HCL and PANI- $\mathrm{H}_{2} \mathrm{SO}_{4}$ in this temperature range $(433-523 \mathrm{~K})$, i.e. the doping level of PANI with $\mathrm{HCOOH}$ is the highest between the other dopants used in this context. The loss in the third step is within $723-873 \mathrm{~K}$.

\section{Conclusions}

Among the three dopants selected in this work, $\mathrm{HCOOH}$ is the best dopant for PANI matrix. FTIR spectra results show that the doping level of PANI-HCOOH is somewhat higher than that of PANI-HCl and PANI$\mathrm{H}_{2} \mathrm{SO}_{4}$ respectively. Therefore, these FTIR results agree with thermo gravimetric analysis (TGA), which also indicates that the doping level of PANI with $\mathrm{HCOOH}$ is higher than that of PANI with $\mathrm{HCl}$ and $\mathrm{H}_{2} \mathrm{SO}_{4}$ respectively. A successful doping of $\mathrm{HCOOH}$ in PANI was observed in uv-visible spectrophotometric analysis. The steric effect of $-\mathrm{COOH}$ group for the formic acid which causes the lower degree of conjugation as well as the hindering charge transfer between chains; this indicates a successful doping of $\mathrm{HCOOH}$ in the polyaniline.

\section{References}

[1] Macdiarmid A.: Appl. Phys., 2001, 1, 269.

[2] Genies E., Boyle A., Lapkowski M. and Tsintavis C.: Synth. Met., 1990, 36, 139.

[3] Macdiarmid A., Chiang J., Halperin M. et al.: Mol. Crystallogr. Liq. Crys., 1985, 121, 173.
[4] Huang J. and Kaner B.: J. Am. Chem. Soc., 2004, 126, 851.

[5] Catedral M., Tapia A. et al.: J. Sci. Diliman, 2004, 16, 41.

[6] Hosseini S., Dabiri M. and Ashrafi M.: Polym. Int., 2006, 55, 1081.

[7] Sharma H.: M.Sc. thesis , Dr. Y.S.Parmar Univ. of Horticulture \& Forestry, India 2006.

[8] Hosseini S., Simiari J. and Farhadpour B.: Iran. Polym. J. , 2009, 18,3 .

[9] Reddya K., Sina B., Ryua K. et al.: Synth. Met., 2009, 159, 1934.

[10] Vivekanandan J., Ponnusamy V., Mahudeswaran A. and Vijayanand P.: Arch. Appl. Sci. Res., 2011, 36, 147.

[11] Zareh E., Moghadam P., Azariyan E. and Sharifian I.: Iran. Polym. J., 2011, 20, 319.

[12] Bitencourt A., Barros U., Maria C. and Leite D.: Int. J. Anal. Chem., 2012, 116, 1567.

[13] Syed A. and Dinesan M.: Talanta, 1991, 38, 815.

[14] Athawale A. and Kulkarni M.: Sens. Actuators B, 2000, 67, 173.

[15] Huang W., Humphery B. and MacDiarmid A.: J. Chem. Soc., FaradayTrans., 1986, 82, 2385.

[16] Stafstrom S., Bredas J., Epstein A. et al.: Phys. Rev. Lett., 1987, 59, 1464.

[17] MacDiarmid A. and Epstein A.: Faraday Discuss., 1989, 88, 317.

[18] Zilberman M., Titelman G., Siegmann A. et al.: J. Appl. Polym. Sci., 1997, 66, 243.

[19] Tazou K. and Gregory R.: Synth. Met., 1993, 53, 365.

[20] Shannon K. and Fernandez J.: Chem. Soc. Chem. Commun., 1994, 643.

[21] Li Y., Cao Y. and Xue Z.: Synth. Met., 1987, 20, 141.

[22] Yang S., Chen W. and You K.: Synth. Met., 1997, 87, 77.

[23] Gomes E. and Oliveira M.: Am. J. Polym. Sci., 2012, $2,5$.

[24] Hasan S. and Hussein Z.: IJAIEM, 2014, 3, 786.

[25] Chabukswar V., Bhavsar S. and Horne A.: Chem. Chem. Technol., 2011, 5, 37.

[26] Chabukswar V. and Sable G.: Chem. Chem. Technol. 2009, 3, 95.

[27] Tzou K. and Gregory R.: Synth. Met., 1993, 53, 365.

[28] Hatchett D., Josowicz M. et al.: Phys. Chem. B, 1999, 103, 10992.

[29] Medhat I. and Eckhard K.: Acta Chim. Slov., 2005, 52, 159.

[30] Bernard M. and Goff H.: Electrochimica Acta, 2006, 52, 595.

[31] Brozova L., Holler P., Kovarova J. et al.: Polym. Degrad. Stabil., 2008, 93, 592.

\section{ДОСЛІДЖЕННЯ ВПЛИВУ ДОПАНТІВ НА СТРУКТУРУ ПОЛІАНІЛІНУ}

Анотація. Оксидаційною полімеризацією синтезований поліанілін (ПАНІ) з додатками хлорної (HCl), сульфатної $\left(\mathrm{H}_{2} \mathrm{SO}_{4}\right)$ і мурашиної кислоти (НСООН). Біхромат калію використовується як окиснювач. Отримані продукти охарактеризовані за допомогою Фур`с та УФ-спектроскопії. Показано, що найкраші результати отримані при додаванні НСООН, щзо підтверджується УФ-спектроскопією. За допомогою термогравиметричного аналізу визначено три стадії розкладу.

Ключові слова: поліанілін, провідність, термічний аналіз, Фур'є-спектроскопія, допант. 